\title{
Are patient-related pre-operative factors influencing return to work after total knee arthroplasty
}

\author{
Petteri Lankinen $^{\mathrm{a}, *}$, Raul Laasik ${ }^{\mathrm{b}}$, Mika Kivimäki ${ }^{\mathrm{c}, \mathrm{d}, \mathrm{e}}$, Ville Aalto $^{\mathrm{c}}$, Mikhail Saltychev ${ }^{\mathrm{f}}$, \\ Jussi Vahtera ${ }^{\mathrm{g}, 1}$, Keijo Mäkeläa ${ }^{\mathrm{a}, 1}$ \\ a Department of Orthopedics and Traumatology Turku, Turku University Hospital and University of Turku, Turku, Finland \\ b Department of Surgery, Satakunta Central Hospital, Pori, Finland \\ c Finnish Institute of Occupational Health, Helsinki, Finland \\ d Clinicum, Faculty of Medicine, University of Helsinki, Helsinki, Finland \\ e Department of Epidemiology and Public Health, University College London, London, UK \\ ${ }^{\mathrm{f}}$ Department of Physical and Rehabilitation Medicine, Turku University Hospital and University of Turku, Turku, Finland \\ ${ }^{g}$ Department of Public Health, University of Turku, Turku, Finland
}

\section{A R T I C L E I N F O}

\section{Article history:}

Received 5 February 2018

Received in revised form 8 February 2019

Accepted 18 April 2019

Available online $\mathrm{xxxx}$

\section{Keywords:}

Total knee arthroplasty (TKA)

Return to work

\begin{abstract}
A B S T R A C T
Background: Osteoarthritis is one of the leading causes of disability in working-age patients. The total number of working-age patients undergoing total-knee arthroplasty (TKA) is continuously increasing. The purpose of this study was to identify predictive factors related to general health, health risk behaviors and socioeconomic status influencing the rate of return to work after a TKA.

Methods: Overall there were 151,901 patients included in the Finnish Public Sector (FPS) study. The response rate varied between 65 and 73\% during the study period. We used Cox proportional hazard models to examine patient-related predictive factors that may influence the rate of return to work after TKA in a cohort of patients $(n=452 ; n=362$ female; mean age 56.4 years). Predictive factors were measured on average 3.6 years before the operation. Results: Of the patients, $87 \%$ returned to work within one year after TKA at a mean of 116 calendar days. In multivariate analysis, patients at sick-leave $\leq 30$ days during the last year before surgery were 2.2 times (95\% confidence interval 1.72-2.92) more likely to return to work compared with those with $>30$ days of sick-leave. Compared with patients in manual work, those in higher or lower level non-manual work showed a 2.6-fold (1.95-3.52) and 1.5-fold (1.15-1.92) increased probability of returning to work. Age, sex, health risk behaviors, obesity, physical comorbidities, common mental disorders, and other studied health-related factors were not associated with the rate of return to work.

Conclusions: Non-manual job, good self-rated general health and preoperative sick leave $\leq 30$ days are associated with a higher rate of return to work.
\end{abstract}

(c) 2019 Elsevier B.V. All rights reserved.

\section{Introduction}

Osteoarthritis is one of the leading causes of disability in working-age patients [1,2]. Total knee arthroplasty (TKA) is a cost-effective treatment modality that relieves pain, restores function, improves mobility, and improves health-related quality of life of patients with

\footnotetext{
* Corresponding author at: Department of Orthopedics and Traumatology Turku, University Hospital and University of Turku, PL 28, 20701 Turku, Finland. E-mail address: petteri.lankinen@tyks.fi. (P. Lankinen).

${ }^{1}$ These senior authors contributed equally to this work.
} 
end-stage osteoarthritis when conservative treatment modalities fail [3-6]. In western countries, the total number of patients undergoing total hip or knee arthroplasty has increased dramatically during the last decades, and it has been estimated that the annual rate of TKA in 2030 will be nearly seven times the rate in 2005 [7-9]. In developed countries, e.g., Finland and Australia, every fifth to seventh man and woman undergoes TKA during their lifetime [10].

Of the patients undergoing total hip or knee arthroplasty, 15-45\% are people of working age [11]. In 2009, it was projected that demand for TKA in patients below age 65 years would exceed 50\% of all patients by 2016 in the USA [12]. In the past, total joint arthroplasty has been associated with inferior results in younger and physically active patients. However, the advances in surgical techniques and prosthesis models has led to expanding clinical indications for arthroplasty to meet physically active younger people who are suffering from osteoarthritis [13-16].

Return to work is an important marker of successful TKA for patients [1,11,17-19]. Return to work affects positively patients' physical and mental health and is beneficial socially and economically for the patients, the employers and the society [20-22]. It has been suggested that on average $70 \%$ of patients in working age undergoing TKA return to work and up to 50\% return to work within three months [23]. With increasing numbers of TKA in younger age groups combined with policies to extend work careers to avoid 'the pensions crisis' and higher expectations for mobility after TKA among patients, there is growing need for evidence on the predictors of return to work after a knee replacement. Rapid increase in obesity, a risk factor of osteoarthritis and surgical complications [24,25], further increases the need to identify factors that predict the outcome of knee replacement. Thus far, the majority of studies have examined predictors of the clinical outcome and the risk of complications related to TKA [4,26-30]. In contrast, less is known on the predictors of return to work after knee replacement [11,31].

The objective of this study was to identify predictive factors related to general health, health risk behaviors, and socioeconomic status associated with the rate of return to work after TKA in a large nation-wide cohort of public-sector employees.

\section{Methods}

The population was from the Finnish Public Sector (FPS) study [32]. The cohort comprises employees of 10 municipalities and six hospital districts. The participants had been employed for minimum of six months in the participating organizations between 1991 and 2005 ( $n=151,901$ ). The cohort covered a wide range of occupations - from city mayors and doctors to semi-skilled cleaners, nurses, and teachers. Since 1997, repeat survey data has been collected from all permanent and long-term temporary employees with two- to four-year intervals. Information on baseline characteristics before the surgery was derived from repeated surveys, employers' records, and national health registers. All participants have been linked to surgical data on TKA from the National Care Register for Health Care, maintained by the National Institute for Health and Welfare as well as the national sickness absence register maintained by the Social Insurance Institution of Finland. The ethics committee of the Hospital District of Helsinki and Uusimaa approved the study.

\subsection{Type of surgery and patient characteristics}

Of the FPS cohort participants, 1996 underwent a single total knee replacement between 1999 and 2011 (Figure 1). Of them, we selected for this study those 452 ( $n=90$ male; $n=362$ female; mean age 56.4 years, standard deviation (SD) 5.1) participants who had responded to a survey before the surgery (Figure 1 ). The response rate varied between $65 \%$ and $73 \%$ during the study period. Predictive factors were measured on average 3.6 (SD 2.1) years before the operation. The mean time from operation the end of follow-up was 4.3 years (SD 2.6). The type of surgery was defined as NGB10, NGB20, NGB30, NGB40, NGB50, NGB60, or

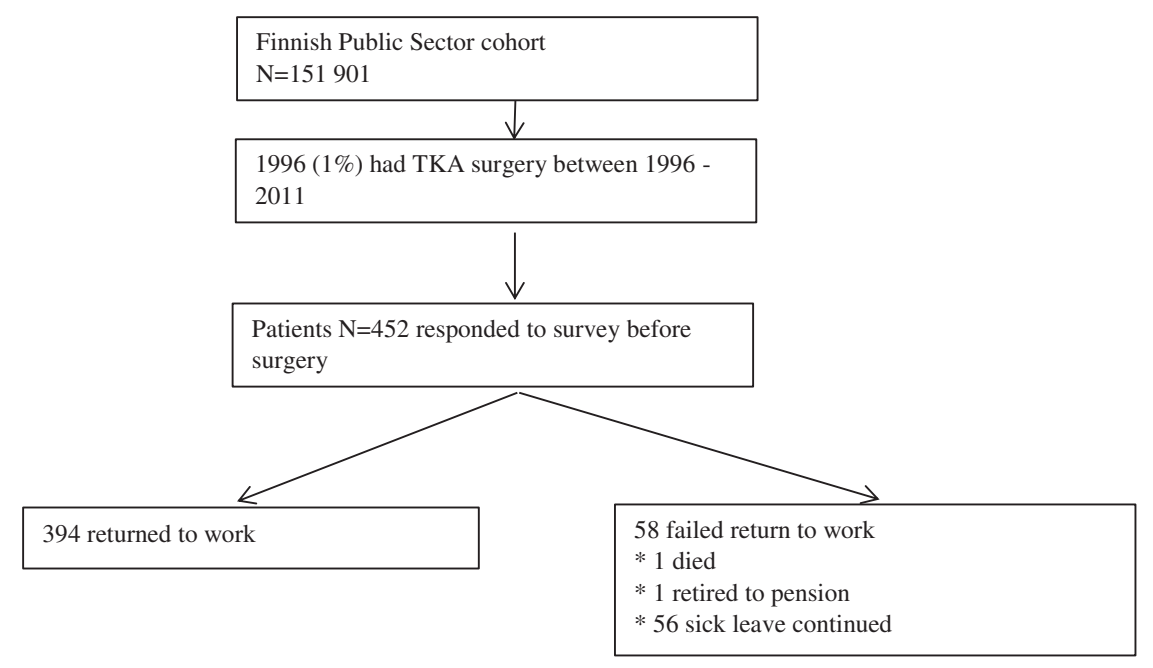

Figure 1. Flow chart of the selection of the analytical sample. 
NGB99 according to the NOMESCO (Nordic Medico-Statistical Committee) Classification of Surgical Procedures Version 1.14 by NOMESCO.

\subsection{Return to work}

Return to work was determined as the number of days between the date of discharge and the date of the end of the sick leave within one year. One patient died, one patient had a disability pension, and in 56 patients, sick leave continued after the first postoperative year (Figure 1). Survey responses were linked to the national sickness absence register kept by the Social Insurance Institution of Finland using personal identification numbers. Finnish residents aged 16-67 years are legitimized to receive daily allowances due to medically certified sickness absence. After a qualifying period of the first nine days of illness, compensation is paid based on salary for a maximum of one year. All sickness absence periods are medically certified, and they are encoded to the register with start and end dates. Overlapping and consecutive periods of sick leave were merged. The linkage data were available until 31 December 2011.

\subsection{Predictors of return to work}

The participants' sex, age, and occupational grade at the time of the surgery were obtained from the employers' registers. Based on the International Classification of Occupations (ISCO), we grouped the occupations into 'higher-grade non-manual workers' (= ISCO classes 1-2; including, e.g., managers, teachers, and physicians), lower-grade non-manual workers (ISCO classes 3-4, e.g., registered nurses, technicians), and manual workers (ISCO classes 5-9, e.g., cleaners, maintenance workers) [33]. Marital status (married or cohabiting vs. single, divorced, or widowed) was obtained from the baseline questionnaire.

Information on behavioral health risks and perceived health was obtained from the baseline questionnaire. Physical activity was defined as average weekly hours of leisure-time physical activity (walking, brisk walking, jogging and running, or respective), including commuting, during the previous year [34]. The hours per week spent on activity at each intensity level were multiplied by the average energy expenditure of each activity expressed as metabolic equivalent of task (MET). Physical activity was categorized into two groups, 'low' ( $\leq 14 \mathrm{MET}$ h/week) and 'high' activity ( $>14 \mathrm{MET}$ h/week). Alcohol consumption was categorized according to the habitual frequencies of drinking beer, wine and spirits as 'none', 'moderate', and 'heavy' consumption. The cut-off for heavy alcohol consumption was set as $210 \mathrm{~g} /$ week [35]. Smoking status was dichotomized as 'currently smoking' vs. 'quitted or never smoked'. Self-reported body weight and height were used to calculate a body mass index (BMI) in $\mathrm{kg} / \mathrm{m}^{2}$, which was used to identify obese (BMI $\geq 30 \mathrm{~kg} / \mathrm{m}^{2}$ ) and non-obese (BMI $<30 \mathrm{~kg} / \mathrm{m}^{2}$ ) participants. Psychological distress was measured with the 12 -item version of the General Health Questionnaire (GHQ) [36] with three or more positive responses set as a cut-off point of psychological distress ('no' vs. 'yes'). Participants rated their state of health on a five-point scale ( $1=$ good, $\ldots 5=$ poor $)$, and the self-rated health was then dichotomized by categorizing response scores 1 and 2 as good health and scores $3-5$ as poor health.

Prevalent diabetes, coronary heart disease, asthma, chronic obstructive pulmonary disease, and rheumatoid arthritis were derived from the Drug Reimbursement Register, which contains information on all persons entitled to special reimbursement for treatment of chronic health conditions. The presence of comorbidity was then dichotomized as 'yes' vs. 'no'.

\subsection{Statistical analysis}

The participants were followed from the date of discharge to the date when an employee returned to work, was granted a disability pension, an old-age pension, died, or the end of the study (31 December 2011), whichever came first. Cox proportional hazard models were used to study the associations between baseline characteristics and return to work. We first examined the associations separately for each predictors adjusted for age and sex. Then we examined the associations mutually adjusted in a single model including all the predictors simultaneously. The results were presented as hazard ratios (HRs) and their 95\% confidence intervals $(95 \% \mathrm{CI}$ ). Survival plot analyses (Figure 2) of preoperative sickness absence (a), occupational status (b) and selfreported health (c) were Kaplan-Meier graphs prepared using Proc Lifetest. All analyses were performed using the SAS statistical software, version 9.1.3 (SAS Institute, Inc., Cary, NC, USA).

\section{Results}

Of the FPS cohort ( $\mathrm{n}=151,901)$ participants, 1996 patients underwent a single total knee replacement between 1999 and 2011 (Figure 1). Of them, 452 participants who had responded to a survey before the surgery (average response rate 65-73\% during the study period) were included in the study. Predictive factors were measured on average 3.6 (SD 2.1, range 1.0-12.0) years before the operation. The mean time from operation the end of follow-up was 4.3 years (SD 2.6, range 0.2-12.4).

The characteristics of the 452 patients are shown in Table 1. The majority (80\%) were women, and 52\% were employed in manual jobs. The average age at the time of surgery was 56.4 (SD 5.1) years. About $40 \%$ of the participants were obese or physically inactive, rated their general health as poor, and were psychologically distressed at baseline. One-fifth had a comorbid chronic medical condition. After the surgery, 87\% $(n=394)$ of patients returned to work on average after 116 (SD 53, range 28-356) days of sickness absence. For the whole study population, mean time of return to work was 142 days (SD 92, range 21-366). 

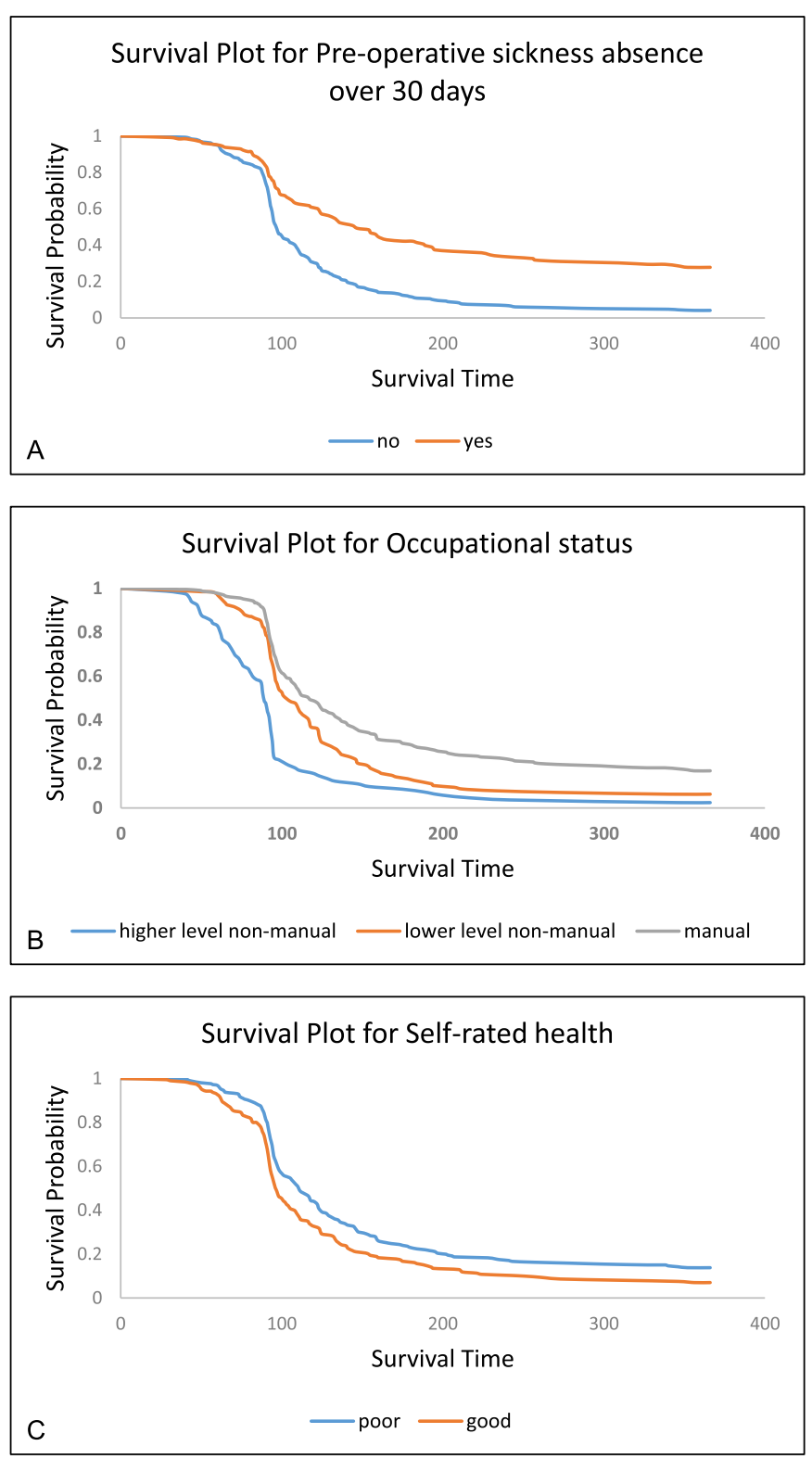

Figure 2. Survival plot analyses of preoperative sickness absence (a), occupational status (b) and self-reported health (c). For patients with $>30$ days of sickness absence within the one-year period preceding the operation, the median postoperative sick leave was 146 days; and for patients with $<30$ days of preoperative sickness absence the median postoperative sick leave was 96 days. The median postoperative duration of sickness absence based on occupational status were: higher-level nonmanual 89 days; lower-level non-manual 101 days; manual 115 days. Patients with good self-rated health the median postoperative sick leave was 96 days and for patients with poor self-rated health 110 days.

\subsection{Predictors of return to work}

As shown in Table 1, patients with higher non-manual occupational status had 2.8 (95\% $\mathrm{Cl} 2.2-3.7$ ) times higher rate of return to work as compared with patients with manual labor occupational status adjusted for age and sex (Figure 1). The respective rate ratio for those with lower-grade non-manual occupations was 1.5 (95\% CI 1.2-1.9). Low level of sickness absence ( $<30$ days) before the surgery was associated with a 2.4 (95\% CI 1.9-3.0) times higher rate of return to work as compared with patients with longer sickness absence. Those patients whose self-rated health was good were 1.4 (95\% CI 1.1-1.7) times more likely to return to work comparing to those with poor self-rated general health (Figure 1). In contrast, socioeconomic factors (age, sex, and marital status), health-behavior factors (smoking, physical activity, high alcohol consumption, and obesity), chronic medical comorbidities (asthma, diabetes mellitus, rheumatoid arthritis, and coronary artery disease), and psychological distress were not associated with return to work. The results 
Table 1

Baseline characteristics of the patient and their associations with the rate of return to work after total knee arthroplasty.

\begin{tabular}{|c|c|c|c|c|c|c|c|}
\hline & \multirow{2}{*}{$\frac{\mathrm{TKA}}{\mathrm{n}(\%)}$} & \multicolumn{3}{|c|}{ Separately analyzed ${ }^{*}$} & \multicolumn{3}{|c|}{ Mutually adjusted } \\
\hline & & $\begin{array}{l}\text { Hazard } \\
\text { ratio }\end{array}$ & $\begin{array}{l}95 \% \text { Confidence } \\
\text { intervals }\end{array}$ & $\mathrm{P}$ & $\begin{array}{l}\text { Hazard } \\
\text { ratio }\end{array}$ & $\begin{array}{l}\text { 95\% Confidence } \\
\text { intervals }\end{array}$ & $\mathrm{P}$ \\
\hline Age $^{\dagger}$ (missing $\mathrm{n}=0$ ) & $56.5($ SD 5.1) & 1.01 & $0.99,1.03$ & 0.58 & 1.01 & $0.99,1.03$ & 0.40 \\
\hline \multicolumn{8}{|l|}{ Sex (missing $\mathrm{n}=0$ ) } \\
\hline Men & 90 (19.9) & 1.00 & $0.78,1.29$ & 0.99 & 1.13 & $0.84,1.52$ & 0.43 \\
\hline Women & $362(80.1)$ & 1.00 & & & 1.00 & & \\
\hline \multicolumn{8}{|c|}{ Married or cohabiting (missing $\mathrm{n}=8$ ) } \\
\hline No & $108(24.3)$ & 0.88 & $0.70,1.11$ & 0.26 & 0.94 & $0.72,1.21$ & 0.61 \\
\hline Yes & $336(75.7)$ & 1.00 & & & 1.00 & & \\
\hline \multicolumn{8}{|c|}{ Obese $\left(\mathrm{BMI}>30 \mathrm{~kg} / \mathrm{m}^{2}\right)($ missing $\mathrm{n}=16)$} \\
\hline No & $251(57.6)$ & 1.12 & $0.91,1.37$ & 0.28 & 0.94 & $0.75,1.18$ & 0.60 \\
\hline Yes & $185(42.4)$ & 1.00 & & & 1.00 & & \\
\hline \multicolumn{8}{|c|}{ Current smoking (missing $\mathrm{n}=16$ ) } \\
\hline No & $368(84.4)$ & 1.06 & $0.80,1.40$ & 0.67 & 0.96 & $0.71,1.30$ & 0.80 \\
\hline Yes & $68(15.6)$ & 1.00 & & & 1.00 & & \\
\hline \multicolumn{8}{|c|}{ High alcohol consumption (missing $\mathrm{n}=3$ ) } \\
\hline No & $397(88.4)$ & 1.06 & $0.75,1.48$ & 0.75 & 1.23 & $0.85,1.80$ & 0.28 \\
\hline Yes & $52(11.6)$ & 1.00 & & & 1.00 & & \\
\hline \multicolumn{8}{|l|}{ Comorbidities (missing $\mathrm{n}=0$ ) } \\
\hline No & $369(81.6)$ & 1.26 & $0.97,1.64$ & 0.09 & 1.10 & $0.82,1.48$ & 0.51 \\
\hline Yes & $83(18.4)$ & 1.00 & & & 1.00 & & \\
\hline \multicolumn{8}{|c|}{ Psychological distress (missing $\mathrm{n}=5$ ) } \\
\hline No & $322(72.0)$ & 1.18 & $0.94,1.47$ & 0.16 & 1.15 & $0.90,1.47$ & 0.26 \\
\hline Yes & $125(28.0)$ & 1.00 & & & 1.00 & & \\
\hline \multicolumn{8}{|c|}{ Self-rated health (missing $\mathrm{n}=5$ ) } \\
\hline Good & $191(42.7)$ & 1.40 & $1.14,1.72$ & 0.0012 & 1.18 & $0.93,1.50$ & 0.19 \\
\hline Poor & $256(57.3)$ & 1.00 & & & 1.00 & & \\
\hline \multicolumn{8}{|c|}{$\begin{array}{l}\text { Physically active (MET-hours over } 14 \text { h/week) } \\
\quad(\text { missing } n=5)\end{array}$} \\
\hline Yes & $253(56.6)$ & 1.12 & $0.92,1.37$ & 0.27 & 0.94 & $0.75,1.18$ & 0.61 \\
\hline No & $194(43.4)$ & 1.00 & & & 1.00 & & \\
\hline \multicolumn{8}{|c|}{ Occupational status (missing $\mathrm{n}=4$ ) } \\
\hline Higher level non-manual & $82(18.3)$ & 2.84 & $2.18,3.71$ & $<0.000$ & 2.62 & $1.95,3.52$ & $<0.0001$ \\
\hline Lower level non-manual & 134 (29.9) & 1.50 & $1.19,1.89$ & 1 & 1.49 & $1.15,1.92$ & 0.0023 \\
\hline Manual & $232(51.8)$ & 1.00 & & 0.0006 & 1.00 & & \\
\hline \multicolumn{8}{|c|}{$\begin{array}{l}\text { Preoperative sickness absence }{ }^{\ddagger} \text { (missing } \\
\quad \mathrm{n}=0 \text { ) }\end{array}$} \\
\hline No & $322(71.2)$ & 2.35 & $1.85,2.99$ & $<0.0001$ & 2.24 & $1.72,2.92$ & $<0.0001$ \\
\hline Yes & $130(28.8)$ & 1.00 & & & 1.00 & & \\
\hline \multicolumn{8}{|c|}{ Year of surgery (missing $\mathrm{n}=0$ ) } \\
\hline 2007-2011 & $277(61.3)$ & 1.12 & $0.92,1.38$ & 0.27 & 1.16 & $0.93,1.45$ & 0.20 \\
\hline 1998-2006 & $175(38.7)$ & 1.00 & & & 1.00 & & \\
\hline
\end{tabular}

Hazard ratios and their 95\% confidence intervals are derived from Cox proportional hazard analyses. BMI, body mass index; SD, standard deviation; TKA, total knee arthroplasty.

* Age and sex adjusted if appropriate.

$\dagger$ Increase in age.

* 30 days of sickness absence within the 1 -year period preceding the operation.

from an analysis including all predictors in the same model essentially replicated the results obtained from age and sex-adjusted models with one exception - self-rated health was not associated with return to work in the mutually adjusted model.

\section{Discussion}

The purpose of the current study was to evaluate the rate of return to work and to analyze patient-related factors influencing the rate of return to work after TKA. Almost $90 \%$ of the patients returned to work after a total knee replacement on average 116 days after operation. Favorable predictive factors were non-manual work, low number of preoperative sickness absence days, and good self-rated health. Surprisingly, patients that were in many ways in better physical shape did not return to work earlier than other patients. Indeed, other socioeconomic factors (age, sex, and marital status), behavior-related risk factors (smoking, physical inactivity, high alcohol consumption, and obesity), chronic medical comorbidities (asthma, diabetes mellitus, rheumatoid arthritis, and coronary artery disease), and poor mental health were not associated with return to work.

Total joint arthroplasty is an effective treatment modality for severe pain and functional disability when non-surgical methods fail to provide adequate relief of symptoms due to end-stage osteoarthritis [37,38]. Continued advances in surgical techniques and prosthesis models have expanded clinical indications even for more active people suffering from arthritis [12]. Based on the 
Finnish Arthroplasty register (FAR) in 2015 36.2\% and in 2016 34.5\% of primary TKAs were performed for patients under the age of 65 years. The rise in retirement age in western countries is further increasing the number of working-age patients. In a systematic review, Bieleman et al. [39] reported that patients with hip and knee osteoarthritis generally are able to stay at work, but it is also reported that patients undergoing total hip arthroplasty or TKA are significantly more often on sick leave than the general population both before and after surgery [37,40,41].

Successful return to work has been identified as a crucial outcome marker for patients after TKA $[1,11,17,18]$. Return to work after TKA is influenced by several determinants including state of patient's general health and presence of comorbid diseases, psychosocial and motivational factors, rate of work-related knee demand, and possibility to make adjustments to work tasks. In addition, Hoorntje et al. reported that also patient beliefs and preoperative expectations influence return to work after TKA [42]. Predictors of successful return to work after knee replacement have not been thoroughly studied. To evaluate these contributing factors is especially important for TKA. This is because TKA patients have been reported to have more sick leave in the year before surgery and also because they return to work slower than total hip arthroplasty patients [37,38]. Additionally, TKA patients have reported inferior work performance rates to total hip arthroplasty patients $[43,44]$

The results of the present study are in line with some previous studies, which have found socioeconomic status, knee demanding work, and the duration of sick leave before surgery to be associated with returning to work after knee replacement [37,45-49]. For clinical work, this is highly noteworthy as osteoarthrosis and related disability is common in patients of a low socioeconomic status [16,50,51]. While the rates of TKA are high among those of a low socioeconomic status [52], they have inferior satisfaction rates with surgery outcome and experience more residual symptoms after TKA [53]. Our results partly agree with two previous systematic reviews that suggested age, socioeconomic status, workplace conditions, preoperative sick leave duration, workplace accessibility, participation in workers' 'compensation program to be related to patients' return to work after knee arthroplasty [11,54]. Scott et al. [45] reported that all working patients $<50$ years returned to work after knee replacement, while only half of those of 50-60 years did. As the vast majority of patients in our study were aged 50 years or more, we do not know what the prognosis would have been among young patients. In some aspects, our results contradicted recent findings suggesting that also female sex, obesity, self-reported work-related symptoms, and mental health symptoms explained failing to return to work $[1,46]$.

The reasons for differences between the results of the present and previous studies remain unclear. Part of the reasons might be methodological, e.g., some studies collected predictor data retrospectively several years after the surgery and used self-reports to measure return to work [46]. Societal factors, e.g., differences in national insurance systems may explain part of the diversities. It is possible that sets of relevant predictors may vary in different subgroups, e.g., based on age on sex distribution.

\subsection{Strengths and weaknesses}

The generalizability of these findings may be affected by the differences in national welfare, pension, and workers' compensation schemes [45]. The studied cohort was limited to public-sector employees in a Scandinavian welfare state. The sex distribution of our study participants ( $80 \%$ women) is the same as in our source population (the Finnish Public Sector cohort) [55] and the whole public sector, with few men in the most common occupations, such as teachers, registered nurses, and practical nurses. No data on workplace adjustments before or after the surgery were available. Based on the current data, we were not able to determine whether patients had previous lower limb surgery to the limb that was included the current study. The motivation to return to work, a potentially important factor, remained unknown. However, psychological distress, a correlate of negative emotional traits, was not associated with return to work in our study. No data on possible complications or re-operations, which may have a significant influence on return to work, were available. A further limitation is that that we were not able to assess post-surgery predictive factors, such as patients' activity levels, satisfaction with the outcome, or functional outcome scores. Patient's pre-surgery expectations as well as the patient-healthcare-provider interaction were not known [20]. Compared to previous literature, our study has notable strengths. The large patient sample was drawn from a well-characterized occupational cohort and represented a wide range of occupations with comprehensive data on health and health risk behaviors well before the surgery. All data were linked to reliable national health registers including detailed information on the operation and the beginning and ending dates of all periods of sickness absence enabling accurate estimation of the timing of return to work. Many predictors of return to work, such as occupational status, sickness absences before the operation and comorbid medical conditions, were measured objectively from the registers. In our opinion, the three presented occupational grades provide a good overall classification of occupations' physical natures. However even among different manual occupations, the amount of knee-demanding duties may vary, and the used classification may partly fail to describe these differences. Further population-based research is needed to confirm these findings in other national and occupational settings. Further research may reveal whether the associations found in this study are robust for all subgroups of patients with knee implants especially, for example, concerning different age groups, different types of prosthesis designs, and factors related to primary indication for surgery such as work-related post-traumatic state.

\section{Conclusions}

Nearly nine of 10 working-aged patients returned to work after TKA. Non-manual job, good self-rated general health and preoperative sick-leave $\leq 30$ days predicted a higher rate of return to work. Manual workers with prolonged sick leave before the total knee replacement were at increased risk of not returning to work after the surgery. These risk factors are to be taken into account when planning TKA and post-surgery rehabilitation. Orthopedic surgeons should consider referring patients at risk for no return to work for additional work-directed care. 


\section{Conflict of interest}

Each author certifies that he or she has no commercial association (e.g., consultancies, stock of ownership, equity interest, patent/licensing arrangements, etc.) that might pose a conflict of interest in connection with this article. M. Kivimäki is supported by NordForsk, the Academy of Finland (311492) and a Helsinki Institute of Life Science Fellowship.

\section{References}

[1] Styron JF, Barsoum WK, Smyth KA, Singer ME. Preoperative predictors of returning to work following primary total knee arthroplasty. J Bone Joint Surg Am 2011; 93:2-10.

[2] U.S. Department of Health and Human Services. Health, United States, 2006 with chartbook on trends in the health of Americans. Hyattsville, MD: National Center for Health Statistics; 2006.

[3] Sankar A, Davis AM, Palaganas MP, Beaton DE, Badley EM, Gignac MA. Return to work and workplace activity limitations following total hip or knee replacement. Osteoarthr Cartil 2013;21:1485-93.

[4] Kane RL, Saleh KJ, Wilt TJ, Bershadsky B. The functional outcomes of total knee arthroplasty. J Bone Joint Surg Am 2005;87:1719-24.

[5] Heck DA, Robinson RL, Partridge CM, Lubitz RM, Freund DA. Patient outcomes after knee replacement. Clin Orthop Relat Res 1998;356:93-110.

[6] Lavernia CJ, Guzman JF, Gachupin-Garcia A. Cost effectiveness and quality of life in knee arthroplasty. Clin Orthop Relat Res 1997;345:134-9.

[7] Kurtz SM, Ong KL, Lau E, Widmer M, Maravic M, Gomez-Barrena E, et al. International survey of primary and revision total knee replacement. Int Orthop 2011;35: $1783-9$.

[8] Kim S. Changes in surgical loads and economic burden of hip and knee replacements in the US: 1997-2004. Arthritis Rheum 2008;59:481-8.

[9] Kurtz S, Ong K, Lau E, Mowat F, Halpern M. Projections of primary and revision hip and knee arthroplasty in the United States from 2005 to 2030. J Bone Joint Surg Am 2007;89:780-5.

[10] Ackerman IN, Bohensky MA, de Steiger R, Brand CA, Eskelinen A, Fenstad AM, et al. Substantial rise in the lifetime risk of primary total knee replacement surgery for osteoarthritis from 2003 to 2013: an international, population-level analysis. Osteoarthr Cartil 2017;25:455-61.

[11] Tilbury C, Schaasberg W, Plevier JW, Fiocco M, Nelissen RG, Vliet Vlieland TP. Return to work after total hip and knee arthroplasty: a systematic review. Rheumatology (Oxford) 2014;53:512-25.

[12] Kurtz SM, Lau E, Ong K, Zhao K, Kelly M, Bozic KJ. Future young patient demand for primary and revision joint replacement: national projections from 2010 to 2030. Clin Orthop Relat Res 2009;467:2606-12.

[13] Glebus GP, Feather TW, Hsu JR, Gerlinger TL. Return to duty and deployment after major joint arthroplasty. J Arthroplasty 2013;28:1270-3.

[14] Nunley RM, Ruh EL, Zhang Q Della Valle CJ, Engh Jr CA, Berend ME, et al. Do patients return to work after hip arthroplasty surgery. J Arthroplasty 2011;26:92,98. e1-e3.

[15] Belmont Jr PJ, Heida K, Keeney JA, Hamilton W, Burks R, Waterman BR. Return to work and functional outcomes following primary total knee arthroplasty in U.S. military service members. J Arthroplasty 2015;30:968-72.

[16] Dorr LD, Luckett M, Conaty JP. Total hip arthroplasties in patients younger than 45 years. A nine- to ten-year follow-up study. Clin Orthop Relat Res 1990;260: 215-9.

[17] Lombardi Jr AV, Nunley RM, Berend KR, Ruh EL, Clohisy JC, Hamilton WG, et al. Do patients return to work after total knee arthroplasty? Clin Orthop Relat Res 2014;472:138-46.

[18] Foote JA, Smith HK, Jonas SC, Greenwood R, Weale AE. Return to work following knee arthroplasty. Knee 2010;17:19-22.

[19] Witjes S, van Geenen RC, Koenraadt KL, van der Hart CP, Blankevoort L, Kerkhoffs GM, et al. Expectations of younger patients concerning activities after knee arthroplasty: are we asking the right questions? Qual Life Res 2016;26(2):403-17.

[20] Bardgett M, Lally J, Malviya A, Deehan D. Return to work after knee replacement: a qualitative study of patient experiences. BMJ Open 2016;6:e007912.

[21] Ruiz Jr D, Koenig L, Dall TM, Gallo P, Narzikul A, Parvizi J, et al. The direct and indirect costs to society of treatment for end-stage knee osteoarthritis. J Bone Joint Surg Am 2013;95:1473-80.

[22] Liang MH, Cullen KE, Larson MG, Thompson MS, Schwartz JA, Fossel AH, et al. Cost-effectiveness of total joint arthroplasty in osteoarthritis. Arthritis Rheum 1986; 29:937-43.

[23] Kievit AJ, van Geenen RC, Kuijer PP, Pahlplatz TM, Blankevoort L, Schafroth MU. Total knee arthroplasty and the unforeseen impact on return to work: a crosssectional multicenter survey. J Arthroplasty 2014;29:1163-8.

[24] Reyes C, Leyland KM, Peat G, Cooper C, Arden NK, Prieto-Alhambra D. Association between overweight and obesity and risk of clinically diagnosed knee, hip, and hand osteoarthritis: a population-based cohort study. Arthritis Rheumatol 2016;68(8):1869-75.

[25] Martin JR, Jennings JM, Dennis DA. Morbid obesity and total knee arthroplasty: a growing problem. J Am Acad Orthop Surg 2017;25(3):188-94.

[26] Lim JT, Luscombe KL, Jones PW, White SH. The effect of preoperative symptom severity on functional outcome of total knee replacement - patients with the lowest preoperative scores achieve the lowest marks. Knee 2006;13:216-9.

[27] SooHoo NF, Lieberman JR, Ko CY, Zingmond DS. Factors predicting complication rates following total knee replacement. J Bone Joint Surg Am 2006;88:480-5.

[28] Caracciolo B, Giaquinto S. Determinants of the subjective functional outcome of total joint arthroplasty. Arch Gerontol Geriatr 2005;41:169-76.

[29] Ibrahim SA, Stone RA, Han X, Cohen P, Fine MJ, Henderson WG, et al. Racial/ethnic differences in surgical outcomes in veterans following knee or hip arthroplasty. Arthritis Rheum 2005;52:3143-51.

[30] Jones CA, Voaklander DC, Suarez-Alma ME. Determinants of function after total knee arthroplasty. Phys Ther 2003;83:696-706.

[31] Pahlplatz TMJ, Schafroth MU, Kuijer PPFM. Patient-related and work-related factors play an important role in return to work after total knee arthroplasty: a systematic review. J ISAKOS 2017;2:127-32.

[32] Airaksinen J, Jokela M, Virtanen M, Oksanen T, Pentti J, Vahtera J, et al. Development and validation of a risk prediction model for work disability: multicohort study. Sci Rep 2017;7:13578.

[33] Statistics Finland. Classification of Occupations. , vol. 14Helsinki: Statistics Finland; 1987.

[34] Kujala UM, Kaprio J, Sarna S, Koskenvuo M. Relationship of leisure-time physical activity and mortality: the Finnish twin cohort. JAMA 1998;279:440-4.

[35] Rimm EB, Williams P, Fosher K, Criqui M, Stampfer MJ. Moderate alcohol intake and lower risk of coronary heart disease: meta-analysis of effects on lipids and haemostatic factors. BMJ 1999;319:1523-8.

[36] Goldberg DP, Gater R, Sartorius N, Ustun TB, Piccinelli M, Gureje O, et al. The validity of two versions of the GHQ in the WHO study of mental illness in general health care. Psychol Med 1997;27:191-7.

[37] Stigmar K, Dahlberg LE, Zhou C, Jacobson Lidgren H, Petersson IF, Englund M. Sick leave in Sweden before and after total joint replacement in hip and knee osteoarthritis patients. Acta Orthop 2017;88:152-7.

[38] Villadsen A, Overgaard S, Holsgaard-Larsen A, Christensen R, Roos EM. Postoperative effects of neuromuscular exercise prior to hip or knee arthroplasty: a randomised controlled trial. Ann Rheum Dis 2014;73:1130-7.

[39] Bieleman HJ, Bierma-Zeinstra SM, Oosterveld FG, Reneman MF, Verhagen AP, Groothoff JW. The effect of osteoarthritis of the hip or knee on work participation. J Rheumatol 2011;38:1835-43.

[40] Turkiewicz A, Gerhardsson de Verdier M, Engstrom G, Nilsson PM, Mellstrom C, Lohmander LS, et al. Prevalence of knee pain and knee OA in southern Sweden and the proportion that seeks medical care. Rheumatology (Oxford) 2015;54:827-35.

[41] Jämsen E, Peltola M, Eskelinen A, Lehto MU. Comorbid diseases as predictors of survival of primary total hip and knee replacements: a nationwide register-based study of 96754 operations on patients with primary osteoarthritis. Ann Rheum Dis 2013;72:1975-82. 
[42] Hoorntje A, Leichtenberg CS, Koenraadt KLM, van Geenen RCI, Kerkhoffs GMMJ, Nelissen RGHH, et al. Not physical activity, but patient beliefs and expectations are associated with return to work after total knee arthroplasty. J Arthroplasty 2018;33(4):1094-100.

[43] Leichtenberg CS, Tilbury C, Kuijer P, Verdegaal S, Wolterbeek R, Nelissen R, et al. Determinants of return to work 12 months after total hip and knee arthroplasty. Ann R Coll Surg Engl 2016;98:387-95.

[44] Kleim BD, Malviya A, Rushton S, Bardgett M, Deehan DJ. Understanding the patient-reported factors determining time taken to return to work after hip and knee arthroplasty. Knee Surg Sports Traumatol Arthrosc 2015;23:3646-52.

[45] Scott CEH, Turnbull GS, MacDonald D, Breusch SJ. Activity levels and return to work following total knee arthroplasty in patients under 65 years of age. Bone Joint J 2017;99-B:1037-46.

[46] Kuijer PP, Kievit AJ, Pahlplatz TM, Hooiveld T, Hoozemans MJ, Blankevoort L, et al. Which patients do not return to work after total knee arthroplasty? Rheumatol Int 2016;36:1249-54.

[47] Malviya A, Wilson G, Kleim B, Kurtz SM, Deehan D. Factors influencing return to work after hip and knee replacement. Occup Med (Lond) 2014;64:402-9.

[48] Lyall H, Ireland J, El-Zebdeh MY. The effect of total knee replacement on employment in patients under 60 years of age. Ann R Coll Surg Engl 2009;91:410-3.

[49] Jorn LP, Johnsson R, Toksvig-Larsen S. Patient satisfaction, function and return to work after knee arthroplasty. Acta Orthop Scand 1999;70:343-7.

[50] Callahan LF, Shreffler J, Siaton BC, Helmick CG, Schoster B, Schwartz TA, et al. Limited educational attainment and radiographic and symptomatic knee osteoarthritis: a cross-sectional analysis using data from the Johnston County (North Carolina) Osteoarthritis Project. Arthritis Res Ther 2010;12:R46.

[51] Thumboo J, Chew LH, Lewin-Koh SC. Socioeconomic and psychosocial factors influence pain or physical function in Asian patients with knee or hip osteoarthritis. Ann Rheum Dis 2002;61:1017-20.

[52] Wetterholm M, Turkiewicz A, Stigmar K, Hubertsson J, Englund M. The rate of joint replacement in osteoarthritis depends on the patient's socioeconomic status. Acta Orthop 2016;87:245-51

[53] Barrack RL, Ruh EL, Chen J, Lombardi Jr AV, Berend KR, Parvizi J, et al. Impact of socioeconomic factors on outcome of total knee arthroplasty. Clin Orthop Relat Res 2014;472:86-97.

[54] Kuijer PP, de Beer MJ, Houdijk JH, Frings-Dresen MH. Beneficial and limiting factors affecting return to work after total knee and hip arthroplasty: a systematic review. J Occup Rehabil 2009;19:375-81.

[55] Juvani A, Oksanen T, Virtanen M, Salo P, Pentti J, Kivimäki M, et al. Clustering of job strain, effort-reward imbalance, and organizational injustice and the risk of work disability: a cohort study. Scand J Work Environ Health 2018;44(5):485-95. 